\title{
Developing a Pedagogically Meaningful E-tutor Training Program for Cyber Face-to-Face Language Teaching
}

\author{
Nian-Shing Chen ${ }^{1}$, Yuping Wang ${ }^{2}$, Ping-Ju Wu ${ }^{1}$, Mike Levy ${ }^{2}$ \\ ${ }^{I}$ Department of Information Management, National Sun Yat-sen University, Taiwan \\ ${ }^{2}$ School of Languages and Linguistics, Griffith University, Australia \\ nschen@faculty.nsysu.edu.tw,y.wang@griffith.edu.au,ceci.wu@gmail.com,michael.levy@griffith.edu.au
}

\begin{abstract}
This study explores essential processes for developing a pedagogically meaningful e-tutor training program for online synchronous language teaching. The pedagogical values of synchronous cyber classroom for language teaching are addressed and detailed descriptions of an online training program conducted for language teachers in a synchronous classroom teaching environment are presented. Forum postings regarding how teacher participants engaged with these processes and reflections on their own experience are categorized and analyzed to provide evidences for their professional development and competence acquirement. Findings suggest that following the e-tutor training program, all the participants were able to apply the online classroom management skills and online pedagogy learnt to real online teaching practices. Furthermore, they expressed a positive attitude towards the promising future of online synchronous language teaching.
\end{abstract}

\section{Introduction}

Online teaching can be asynchronous-based or synchronous-based; the former provides learning activities such as surfing web contents, participating in forum discussion, and completing online quiz and homework assignments, while the latter provides learning activities which are similar to those conducted in traditional face-to-face classroom. As more sophisticated software are required to support a synchronous cyber classroom with spontaneous interaction, conducting online synchronous teaching presents more and different kinds of challenges than face-to-face classroom teaching $[4,7,13]$. These challenges and the needs for professional training are much more keenly felt by language teachers because language teaching requires constant spontaneous interaction. The importance for providing an adequate training and support for online tutors have long been recognized, and research dealing with specific training courses in areas other than language learning can be found in numerous articles (e.g., [2,3]). However, literature regarding online tutor training for language teachers is still sparse. An online training program with particular focuses on synchronous language teaching is still missing. Furthermore, merely knowing how to use the tools offered by the synchronous platform cannot lead to successful online language teaching because pedagogy is the most important component, as it determines student engagement [1]. Thus, online synchronous teacher training should be pedagogically meaningful. The present study aims to fulfill this urgent need by providing a detailed discussion of such a training program conducted at Griffith University, Australia.

\section{The pedagogical values of synchronous cyber classroom for language teaching}

In this section, we explore the features that synchronous computer mediated communications (SCMC) possesses to activate its pedagogical functions in the context of online language learning. In our analysis of SCMC technologies, a Synchronous Learning Management System (SLMS) called 3C (the Collaborative Cyber Community) was adopted for the training program and we found the following four categories of features to be pedagogically meaningful in language classrooms: features enhancing language learning, features promoting learner autonomy, features supporting learning community, and features enabling team teaching.

\subsection{Features enhancing language learning}

The 3C platform provides a more advanced synchronous cyber classroom which enables all online participants to have cyber face-to-face features with pedagogical values such as the Whiteboard, Sharing, File Transfer, and My Video. The on-screen Whiteboard is a pedagogically valuable feature mostly used for character writing, linguistic explanations, and showing directions during task completions. As a language teacher, it is very important to learn how to use it effectively and creatively. The Sharing function enables teachers to share multiple resources (e.g., programs, files, photos, or documents, etc.) opened on the computer desktop with other participants 
simultaneously. For example, a family photo can be shared as a visual aid when the task performance is about family members. Document delivered through File Transfer, unlike in Sharing, can be either viewed on the spot or kept for future use. My Video is a self-image window on the screen through which one can see him-/herself while watching the video of the other person. This function can be used to ensure learners' participation, interaction and comprehension, and it can also be used to assist paralinguistic cues and negotiation for meaning.

\subsection{Features promoting learner autonomy}

The concept of learner autonomy refers to the idea that students should develop into life-long learners by enhancing their abilities and inclinations to plan, control, and evaluate their own learning [14]. Once students are given the opportunity to have control over their own learning process, learner autonomy can be developed. In addition, certain cooperative learning approaches can also promote a high degree of learner autonomy because they provide students with the freedom to organize group activities [9]. A crucial functionality of the synchronous cyber classroom on $3 \mathrm{C}$ to foster learner autonomy is the video recording. Each synchronous class or online discussion can be recorded for future use, which grants learners chances to make up for a missed class or review the delivered contents whenever and as many times as they want to. This can actually turn a passive learner into an active one as the access to learning materials is no longer controlled by the instructors.

\subsection{Features enabling cooperative learning and team teaching}

Tools such as discussion forums, bulletin boards, subscriptions (requesting email notification when the selected resource has new updates), and sub synchronous cyber classrooms can help students' collaboration that occurs in cooperative learning groups. These features also help cultivate learner autonomy as learners are assigned a stronger role in controlling their own learning process [8]. Some functionalities of the synchronous cyber classroom on 3C are conducive to online team teaching, e.g., onscreen whiteboard, document and window sharing, synchronous text chat, desktop sharing and joint web browsing $[7,13]$.

\subsection{Features supporting learning community}

Among those various tools associated with a community of practice proposed by Wenger, McDermott and Snyder [15], the SLMS platform of 3C offers the following: (1) a conversation space for online discussions; (2) a repository for storing documents; (3) a good search engine to find things in the knowledge base; (4) a directory of membership containing member information; (5) a common shared workspace for synchronous electronic collaboration, or to enhance teleconferences with visual; (6) community management tools. From the perspective of training online language tutors, learning communities have been used effectively to promote educational practice by allowing teachers to engage in discourse with teacher educators and other teachers in a non-threatening manner [6]. SLMS can be viewed as an effective medium through which online tutors can share expertise, try out new ideas, reflect on practices, and develop new curriculum and an online learning/teaching community.

\section{Developing and conducting a training program for online synchronous language teachers}

Despite the pedagogical values a synchronous cyber classroom can foster, many language teachers have expressed their fear and hesitation to make online teaching part of their curriculum, due to their lack of knowledge of the synchronous learning environment. Thus a well-designed and delivered training program for language tutors is crucial. The program conducted in our research is unique because, based on its nature of generalization, it can at the same time fulfill each individual e-tutor's needs because it is evolved through the process of an ongoing training program.

\subsection{Program design}

Our training program was originally designed following the five stages proposed by Salmon [10]. However, Salmon's model is for asynchronous online teaching and learning while our model was designed for both asynchronous and synchronous online teaching and learning, which consisted of the following five stages.

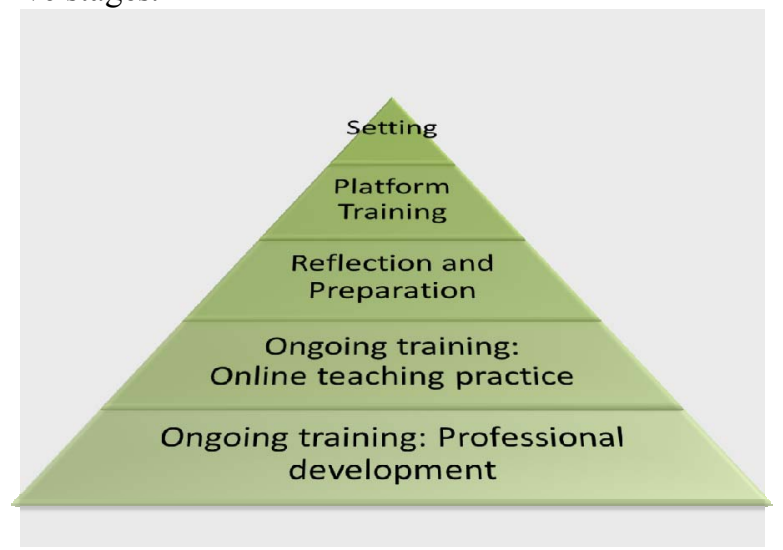

Figure 1. The proposed program design 
Stage one represents the initial system setting up phase. It is at the top of the pyramid and occupies the smallest part of the training program. This happened in a face-to-face workshop. Times for checking individual set up were allocated during which a technician tested each individual's audio and video set-ups.

Stage two is primarily introductory in nature, introducing features in $3 \mathrm{C}$, online synchronous classroom management skills and e-pedagogy (i.e., how to use online feature in language teaching). This phase was conducted solely online. Online socialization also happened in this phase as teachers interacted with each other online for the first time. This is a period that the teachers could be overwhelmed by information overload as they had to cope with the technological, pedagogical and psychological demands.

Stage three is for the trainees to internalize what they have learned in the previous two phases and prepare themselves for the next stage - online teaching practice. In terms of time allocation, this should be the second longest period during the whole training program so that trainees can be adequately prepared. Although no online classes were held, trainees were provided with personalized supports such as office hours for individual consultation, provision of teaching materials, and peer supports, etc.

The forth stage occupies the longest period of time in the entire training program - teaching practice, ideally, with real students. An in-service (ongoing) workshop was conducted half way through the teaching practice to help the trainees to reflect on their online teaching experience and effectively identify and solve problems in their online teaching. The ongoing workshop was not planned originally, but it had become necessary to have such a workshop for reflection of what has been achieved and what needed to pay more attention to, especially when the next stage focused on team teaching. An emphasis during this period of training was on reflection through monitoring reports completed by each of the trainees and the trainer and self reflection reports on completion of each online teaching session. This is a very important mechanism of training.

Stage five is the continuation of training by trainees themselves as the previous four stages have laid a foundation for this stage. This is a stage that can go on for the rest of one's teaching career. In our training program, we only trained the teachers on the basic principles of conducting cyber face-to-face classes. We felt once the teachers can teach the cyber face-to-face classes, they can learn and feel motivated to learning other online teaching skills, e.g., managing forums such as the discussion and announcement forums and using the "teacher's office" for the effective management of a complete course online.. More importantly, their increased expertise and confidence will lead to more creativity in their online teaching and more sensitivity to new developments in the filed.

\subsection{Procedure}

We first sent emails to invite teachers from the major universities in Queensland, Australia, informing them of our first workshop on online language teaching. Among the 10 teachers attending the workshop, eight expressed their intention to participate our training program. The high participation rate was unexpected. The training program mainly consists of two stages, lasting for totally 12 weeks.

Module one is the platform training stage consisting of three 2-hour workshops, with the first being face-to-face and the other two online workshops. The face-to-face workshop was conducted in a language laboratory at Griffith University. The aims of this workshop were (1) to introduce the equipment needed, including webcams and headphones and how to install them, (2) to give a general introduction of $3 \mathrm{C}$ and (3) to build a rapport among the participating teachers. The two workshops that followed were conducted online using 3C. The participants attended the workshops from their homes or offices, while the training was conducted from the trainer's home. The aims of these two online workshops were to further introduce the various functions of $3 \mathrm{C}$, with particular emphasis on using the features (e.g., how to upload files to the whiteboard, how to use the pointer, online poll, discussion group, window capture, Joint Web browsing, and desktop sharing, etc.) in the cyber face-to-face classroom for language teaching. This was followed by a week of self reflection and practice of what had been taught in the workshops. This week was also utilized by the teachers to prepare teaching materials for session two - online teaching practice with real students. To effectively coordinate the teaching activities, teachers were provided with a suggested teaching plan outlining major classroom activities, resources and procedures.

Module two witnessed 8 weeks of online teaching with distance students learning Chinese and one ongoing training workshop. In the first four weeks, each teacher was required to teach 15 minutes individually and then in the last four weeks, teachers were paired to do team teaching for 30 minutes for each team. While one teacher or a teaching team was teaching, others including the trainer were required to observe and complete a monitoring report for each teacher who taught. The teachers teaching that week were also required to complete a self reflection journal, commenting on their own teaching performance. 
A two-hour workshop was held before the start of team teaching in Week 5 of Module two, for reflecting and sharing online teaching experience and for introducing more strategies, especially team teaching strategies. The rationale of holding a workshop in the middle of the teaching practice was that the participants by then would have some experience with online teaching and would be able to apply more of the strategies and relate more to their teaching experience. The workshop was conducted online by one of the researchers, a reputed expert in the field of e-Learning with substantial experience of online teaching. Throughout the training period, a two-hour office time was offered twice a week to deal with individual enquiries and help individual teachers with practicing the cyber face-to-face features and with the preparation for teaching.

\subsection{Reflective practice model}

One important element incorporated in our training program is the use of teacher reflection, which has been widely adopted in most teacher education and professional development programs $[3,5,11]$. Reflection is now regarded as an indispensable component when designing courses for teacher training. The rationale of using reflection in our training model was to make the trainee aware of "what they have learned" (skills and knowledge), and hence to make a connection with "what they need" for the real teaching practice. To effectively combine the two essential parts of our program - practice and reflection, as a reflective cycle (defined as the continuing process of reflection on received knowledge and experiential knowledge in the context of practice), we adopted the original reflective practice model illustrated by Wallace [12]. As self-reflection alone is not adequate for obtaining knowledge about teaching itself, dialogues with colleagues, for example, can also be one of the possibilities to supplement self-reflection. Therefore, we urged that the teacher participants write reflection journals and post them to the discussion forum as a means to communicate and share experiences/opinions with their peers, as well as the program trainer. As for the self-reflection reports, in this study we asked the participants to send them directly to the trainer by email for privacy reasons. However, the peer monitoring reports were first sent to the trainer concerned for responses to comments and were then sent to the trainer for data collection. Through the analysis of the postings and reflection reports of participant teachers, we expect to generate a complete pedagogically meaningful model for future e-tutor training.

\section{Lessons learned and implications}

After completing the training program, we asked all the teacher participants to fill out a final survey, for the purpose of obtaining their opinions on the overall training experience, suggestions for the program design, and perspectives on pedagogical issues. Based on the data we collected from this survey and our own reflections during the process of managing this program, we report the following lessons learned which are extremely valuable for professional development program designers and synchronous language teaching practitioners as summarized in table 1 .

Table 1. Summary of lessons learned

\begin{tabular}{|ll|c|}
\hline \multicolumn{1}{|c|}{ Lessons learned } & Issues \\
\hline$>\quad \begin{array}{l}\text { A well-planned pre-training for } \\
\text { technical skills and } \\
\text { easy-to-access technical supports } \\
\text { are indispensable. }\end{array}$ & $\begin{array}{c}\text { Time } \\
\text { What } \\
\text { Where }\end{array}$ \\
\hline$>\begin{array}{l}\text { An ideal training program has to } \\
\text { include a real synchronous } \\
\text { teaching practice section. }\end{array}$ & $\begin{array}{c}\text { Availability } \\
\text { and stability } \\
\text { of volunteer } \\
\text { students. }\end{array}$ \\
\hline$>\quad \begin{array}{l}\text { A reflective model is proven } \\
\text { beneficial for e-tutor training } \\
\text { program. }\end{array}$ & $\begin{array}{c}\text { A shared } \\
\text { cyberspace is } \\
\text { required. }\end{array}$ \\
\hline
\end{tabular}

First, a well-planned pre-training for technical skills and easy-to-access technical supports are indispensable. The planning of the pre-skill training workshop deals with three issues: time (how long is appropriate), what (the content) and where (the place). Regarding the time and place, there is no absolute correct answer indicating how long is perfect. Generally, the participants thought our 2-hour physical face-to-face workshop was effective and necessary, but the required time really depends on how much they know about the computer and how well they can use it before they join the program. To access the participants' computer skill level, a pre-test and related survey has to be conducted before the workshop. As for the content, it must include both functionality introduction and practice sections. The practice sections, which can be conducted online, are especially necessary and helpful for language teachers who are not that good at computer skills. In addition, supplementary supports, such as office hours and an easy-to-read skill manual with visual aids (explanations together with pictures showing the real thing) are strongly recommended.

Secondly, an ideal training program has to include a real synchronous teaching practice section. The instructional models employed by the $3 \mathrm{C}$ features must incorporate with real teaching to make them 
pedagogical meaningful. Through the teaching practice, teachers not only learned how to apply these $3 \mathrm{C}$ features to a real synchronous language classroom, but also were able to reflect on the usefulness of these features. From the 8 participants' reports on the usefulness of $3 \mathrm{C}$ features, "Whiteboard" was ranked the most useful feature for online synchronous language teaching; "Text chat" was ranked the second place and then the "Shared Desktop". Finally, a reflective model is proven beneficial for e-tutor training program. The mechanism to trigger participants' reflections on the learning and practicing process is extremely important for their development to achieve professional competence. Besides, a shared cyberspace to record and share these valuable reflective journals is also required. Given the central role of teaching practice in learning outcomes, it is obvious that a successful synchronous language classroom is not driven primarily by technology features but rather by instructional models that reflective educators develop and share with their peers. In short, it's the "pedagogical use" instead of the technology itself which makes the technology features meaningful for teaching.

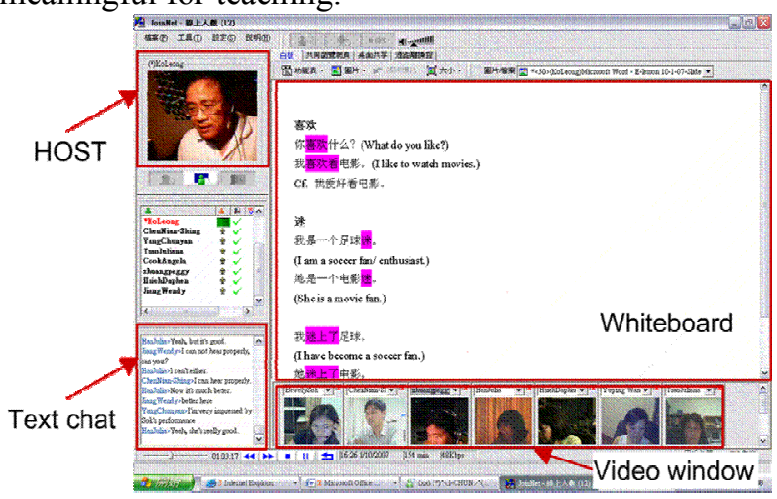

Figure 2. 3C classroom environment

\section{Conclusion}

The Internet has connected billions and billions of people together around the would, many people would need to learn more languages to be able to better communicate with their partners from different parts of the world in the so called the global village society. Online synchronous language learning therefore becomes a very promising application of e-learning. Online synchronous cyber classroom can provide more authentic learning activities for learners to be engaged in listening, speaking, reading and writing. Therefore it is more suitable for online language teaching. Online teachers need to receive adequate training and acquire professional skills before they can really offer effective online language courses. This paper has recognized the need for effective e-tutor training and has attempted to develop a pedagogically meaningful e-tutor training program for online synchronous language teachers.

Acknowledgement: This research is supported by the National Science Council, Taiwan with the contract no. of NSC95-2520-S-110-001-MY2.

\section{References}

[1] Adams, A., "Pedagogical underpinnings of computer-based learning", Journal of Advanced Nursing, 46(1), 2004, pp. 5-12.

[2] Barker, P., "On being an online tutor", Innovations in Education and Teaching International, 39(1), 2002, pp. 3-13.

[3] Bennett, S., \& Marsh, D., "Are We Expecting Online Tutors to Run Before They Can Walk?" Innovations in Education and Teaching International, 39(1), 2002, pp. 14-20.

[4] Chen, N.S., Kinshuk, Ko, H.C., Lin, T.Y., “A Model for Synchronous Learning Using the Internet”, Innovations in Education and Teaching International, 42(2), 2005, pp. 181-194.

[5] Connolly, M., Jones, C., \& Jones, N., "New approaches, new vision: capturing teacher experiences in a brave new online world" , Open Learning: The Journal of Open and Distance Learning, 22(1), 2007, pp. 43-56.

[6] Harrington, H. L., \& Hathaway, R. S., "Computer conferencing, critical reflection, and teacher development" , Teaching and Teacher Education, 10(5), 1994, pp. 543-554.

[7] Hastie, M., Chen, N.S., Kuo, Y.H., "Instructional Design for Best Practice in the Synchronous Cyber Classroom" , Educational Technology \& Society, 10 (4), 2007, pp. 281-294.

[8] Macaro, E., Target language, collaborative learning and autonomy, Clevedon, Avon: Multilingual Matters, 1997.

[9] McCafferty, S. G., Jacobs, G. M., \& DaSilva Iddings, A. C., Cooperative Learning and Second Language Teaching, New York: Cambridge University Press, 2006.

[10] Salmon, G., E-moderating: The key to teaching and learning online (2ed.), London and New York: Routledge Falmer, 2003.

[11] Stickler, U., \& Hampel, R., "Designing online tutor training for language courses: a case study" , Open Learning: The Journal of Open and Distance Learning, 22(1), 2007, pp. 75-85.

[12] Wallace, M. J., Training Foreign Language Teachers: A reflective approach, New York: Cambridge University Press, 1991.

[13] Wang, Y. \& Chen, N.S., “Online synchronous language learning: SLMS over the Internet” , Innovate, 3 (3), retrieved October 15, 2007, from

http://innovateonline.info/index.php?view $=$ article\&id $=337$ [14] Wenden, A., Learner strategies for learner autonomy, London: Prentice-Hall International, 1991.

[15] Wenger, E. C., McDermott, R., \& Snyder, W. C., Cultivating communities of practice: a guide to managing knowledge, Cambridge, MA: Harvard Business School Press, 2002. 